\title{
Injection of Stromal Vascular Fraction Plus Platelet-Rich Plasma in a Non-Healing Decubitus Ulcer
}

\author{
Kristin Comella ${ }^{\mathrm{a}, \mathrm{c}}$, David Ikudayisi ${ }^{\mathrm{b}}$
}

\begin{abstract}
Non-healing decubitus ulcers can be challenging to treat and may often progress to other life-threatening complications. Significant tissue damage is present in stage $3 / 4$ wounds and treatment options can be limited or present additional risks. Applications of regenerative medicine and stem cell therapy are rapidly expanding in particular in the field of non-healing wounds. Adipose tissue is a rich source of autologous stem cells which can be easily isolated in an outpatient visit. The population of cells collected from fat after the adipocytes (fat cells) are removed via centrifugation is called stromal vascular fraction (SVF) and contains mesenchymal/adipose stem cells, fibroblasts, pericytes, endothelial/progenitor cells and more. Adipose tissue is collected under local anesthesia via cannula and SVF is separated via centrifugation after enzyme digestion. In addition, peripheral blood can be centrifuged to collect platelet-rich plasma (PRP) which contains a mixture of cytokines/growth factors. Here we present a first in man case study of a single injection of SVF and PRP into a chronic non-healing stage 3 ulcer in a patient with an incomplete spinal cord injury. After removing approximately $60 \mathrm{~mL}$ of fat tissue, the SVF was isolated and resuspended in approximately $5 \mathrm{~mL}$ of PRP for local administration in the non-healing wound. The wound was monitored and tracked with imaging and the patient was tracked for quality of life parameters as well as safety (adverse events). No complications or other safety events were reported either during the procedure or in the months following the procedure. The patient reported reduction of pain consistent with wound healing and a willingness to repeat therapies if required. The healing stage 3 pressure injury showed clear re-epithelialization. Based on this case study, a feasible treatment plan to promote healing for stage 3 and 4 decubitus ulcers could be a single injection of SVF plus PRP.
\end{abstract}

Keywords: Adipose-derived stromal/stem cells; Decubitus ulcers; Mesenchymal stem cells; Stem cells; Stromal vascular fraction; Platelet-rich plasma

Manuscript submitted July 13, 2018, accepted August 13, 2018

aUS Stem Cell, Inc., 13794 NW 4th Street, Suite 212, Sunrise, FL 33325, USA

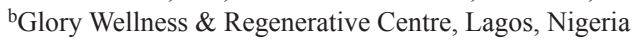

${ }^{\mathrm{c} C o r r e s p o n d i n g ~ A u t h o r: ~ K r i s t i n ~ C o m e l l a, ~ U S ~ S t e m ~ C e l l, ~ I n c ., ~} 13794$ NW 4th Street, Suite 212, Sunrise, FL 33325, USA.

Email: kcomella@us-stemcell.com

doi: https://doi.org/10.14740/jmc3128w

\section{Introduction}

A decubitus ulcer is a wound on the skin also known as a pressure ulcer. Decubitus ulcers typically occur over bony skin such as the buttocks. These wounds can be common in spinal cord injury patients with limited mobility. The number of patients with pressure ulcers is estimated to be approximately $1.3-3$ million in the USA and the number of hospitalized patients has increased by more than 75\% between 1993 and 2006 [1]. Pressure ulcers can be classified according to four stages. Stage 1 is discolored but not broken skin. Stage 2 is a shallow open redpink wound and may have a blister. Stage 3 manifests as a full thickness loss of skin with visible adipose tissue. Stage 4 is full thickness skin and tissue loss with exposed muscle and bone [2].

Mesenchymal/multipotential stem cells or MSCs are thought to have regenerative capacity and can be isolated from a variety of tissue sources including adipose or fat tissue [3-5]. Adipose-derived stem cells (ADSCs) are MSCs which have been collected from fat. Easily accessible subcutaneous fat from the abdomen or the flanks can be collected via mini-lipoaspiration and contains high amounts of ADSCs [6]. Both ADSCs and MSCs are multi-potential cells with ability to differentiate into bone, cartilage, muscle and fat and can be expanded in culture. The expression of different cytokines and growth factors by these cells is thought to be part of a healing cascade and new blood vessel formation. By stimulating a local inflammation process and immunomodulatory/paracrine response, this signaling can enable the repair of damaged tissue [7, 8]. MSCs/ADSCs are currently being considered in various diseases and injuries $[5,9]$. The exploitation of stem cells ability to promote a healing cascade is a new paradigm in medicine. The cells are antiinflammatory and promote angiogenesis $[10,11]$. This complex signaling process causes the homing of other cells to the area to repair damaged tissue and regeneration occurs.

The stromal vascular fraction (SVF) is the mixture of cells from adipose tissue collected via mini-lipoaspiration after the adipocytes (fat cells) have been depleted. The remaining cells include a large percentage of ADSCs. The population is known to have a large percentage of $\mathrm{CD} 34^{+}$cells which have a role in angiogenesis and vasculogenesis [12]. CD34 is a protein expressed on the cellular membrane of ADSCs and pericytes. Fat tissue has a network of microvessels and capillaries which are rich in pericytes $[13,14]$.

It is believed that these cells help to build and maintain an endothelial network. Because SVF contains a variety of re- 
generative cells and growth factors and can be offered as an out-patient surgical procedure, it represents a novel therapeutic tool for many indications. Further, fat tissue is quickly becoming the preferred source for stem cells as compared to bone marrow due to the relative higher amounts of ADSCs/MSCs and lower amounts of pro-inflammatory leukocytes [15].

Local injection of SVF may reduce inflammation and promote healing/normal tissue formation as opposed to scar tissue. SVF can be collected bed side after a simple adipose tissue collection making it a practical surgical procedure for physicians to provide to their patients [16]. Comella et al reported on the safety of SVF in a variety of indications with various delivery methods. Other publications have demonstrated success of SVF for specific conditions including: chronic obstructive pulmonary disease (COPD) [17], congestive heart failure [18], degenerative disc disease [19], osteoarthritis/orthopedics [2024], radiation necrosis [25], sclerosis [26], tendinopathy [27], xerostomia [28], psoriasis [29] and multiple sclerosis [30]. The following is a case report and to our knowledge first in man a single injection of SVF and PRP into a chronic non-healing stage 3 ulcer in a patient with an incomplete spinal cord injury.

\section{Patients and Methods}

The following case report was completed on a 49-year-old male with prior incomplete spinal cord injury with stage 3 decubitus ulcer on the buttocks. The wound had persisted for 8 months with full thickness loss of epidermis and no exposure of underlying bone, muscle or tendon. Prior interventions include wound cleansing with hydrogen peroxide, wound dressing with eusol (bleach, boric acid and water) and gauze, and pressure relief by changing of position in bed.

The patient provided written informed consent to undergo the experimental clinical procedure as well as consent to publication of outcomes, images and data. Using less than $2 \mathrm{~mL}$ of $1 \%$ lidocaine with epinephrine $(1: 100,000)$ and a 30 -gauge 0.5 -inch needle, local infiltration blebs allowed small incisions with a no. 11 blade for cannula entry. Areas to be treated were then infiltrated with a standard tumescent solution $(500 \mathrm{~mL}$ normal saline, $20 \mathrm{~mL}$ of lidocaine $(2 \%), 10 \mathrm{~mL}$ of sodium bicarbonate $(8.4 \%)$ and $1 \mathrm{~mL}$ of epinephrine $(1 \mathrm{mg} / \mathrm{mL}))$ with a 14 gauge $\times 15 \mathrm{~cm}$ infiltration cannula. After good tumescence was achieved, a harvester cannula was introduced through the entry points. Adipose tissue was then aspirated gently using the 2.1-mm small cannula.

The total fat collected was approximately $60 \mathrm{~mL}$ minus the infranate. Using a commercially available collection kit and enzyme (Adipocell ${ }^{\mathrm{TM}}$ Enzyme; US Stem Cell, Inc. Sunrise, FL), the fat was processed to obtain the SVF. Briefly, the fat was washed using a balanced salt solution to remove red blood cells and debris and then placed on enzyme to digest collagen bonds in the extracellular matrix. The SVF was separated by density after centrifugation. After washing, the cells were prepared for final suspension in platelet-rich plasma (PRP).

To create PRP, whole blood was collected via a 22-gauge butterfly needle into ACD solution A blood tubes (BD Vacutainer $($ ). The autologous whole blood was centrifuged at 500 $\mathrm{g}$ for $8 \mathrm{~min}$. Using a $10 \mathrm{~mL}$ syringe and cell extractor, approximately $5 \mathrm{~mL}$ of PRP was collected just above the buffy coat (white ring). The final SVF pellet was resuspended in $5 \mathrm{~mL}$ of PRP. After local numbing with $5 \mathrm{~mL} 1 \%$ lidocaine and $1 \mathrm{~mL}$ bicarbonate, the $5 \mathrm{~mL}$ of the SVF and PRP was injected in 0.25 $\mathrm{mL}$ intervals in and around the ulcer.

The patient was monitored for any safety events including adverse events (AEs) and severe adverse events (SAEs) before, during and following the procedure. SAEs are defined as any fatal or life-threatening events leading to hospitalizations, or requiring major medical interventions. Baseline parameters collected included blood work, blood pressure, weight/height, pulse and photographic imaging of decubitus ulcer. Photographic imaging was also at day 6 , day 21 and 2 months post-injection.

\section{Results}

The entire procedure including the mini-lipoaspiration, the blood collection and the SVF/PRP injection was well tolerated with no reported AEs. During the follow-up period, the patient did not report any AEs or SAEs. Normal activities were resumed in under a week and the patient reported a willingness to repeat therapy should it be necessary. Approximately 30 - 60 million nucleated cells are typically collected from a $60 \mathrm{~mL}$ sample of fat tissue after adipocyte depletion. During the follow-up period, the patient reported satisfaction with the healing process of his wound, reduction of pain until non-painful stage and no AEs. Figure 1a shows photograph of stage 3 decubitus ulcer prior to cell therapy. Figure 1b, taken 6 days after direct injection of SVF plus PRP, shows re-epithelialization of the ulcer. Figure 1c, taken 21 days after injection, shows remodeling. Figure 1d, taken 2 months after injection, shows continual remodeling/maturation.

\section{Discussion}

Decubitus ulcers are a common complication for spinal cord injury patients. Chronic stage 3 and 4 pressure sores can be difficult to heal and lead to life-threatening complications. Recent literature has revealed the anti-inflammatory and healing properties of stem cells. The use of SVF in a clinical outpatient setting for non-healing ulcer wounds could be a novel therapy. Future studies could help to establish appropriate clinical protocols (including repeat dosing or quantity/volume of cells/ PRP) for specific indications.

Given the complex nature of the healing cascade and the lack of understanding of the mechanisms of action of stem cells, it is unclear to what extent this protocol may be successful in other cases. Proposed mechanisms of action in this patient could be an immunomodulary/paracrine effect or engraftment of the injected cells. The injection of the SVF most probably stimulated a reduction of inflammation followed by the formation of new healthy tissue. Complete tissue remodeling as a result of a complex sequence of events is stimulated by expression of growth factors, chemokines and cytokines.

Direct injection of SVF plus PRP in a chronic stage 3 de- 


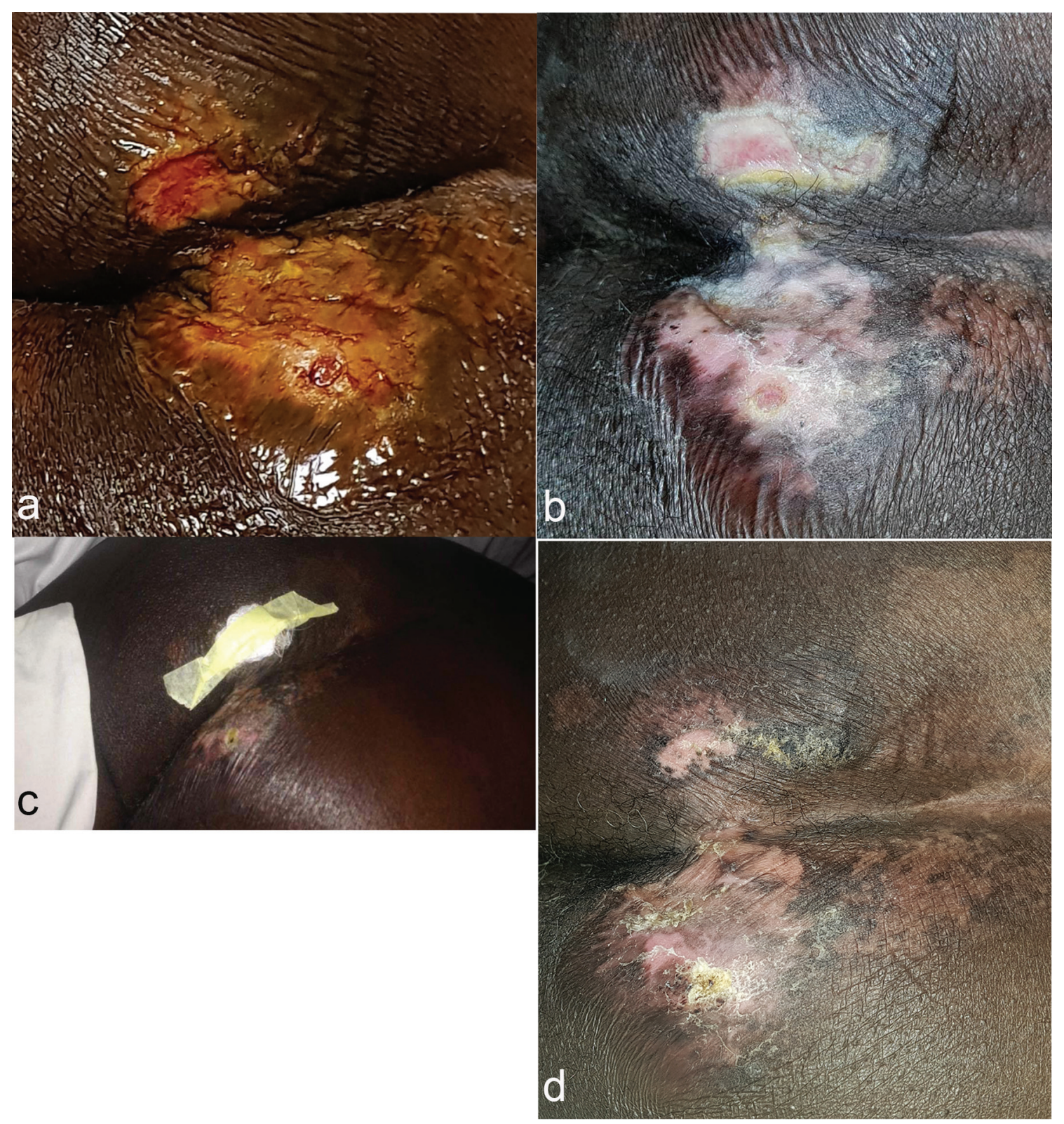

Figure 1. Picture of patients decubitus ulcer at baseline (a), 6 days (b), 21 days (c) and 2 months (d) after direct injection of SVF/ PRP. Clear re-epitheliazation, remodeling and maturation of wound.

cubitus ulcer can be effectively and safely completed in an outpatient setting according to this case study. The patient tolerated the procedure with no reported AEs. Photographic imaging depicted the stages of wound healing after a single injection of the cellular mixture. Anticipated outcomes for wound healing and detailed protocols could be determined with larger clinical studies.

\section{Conflict of Interest}

$\mathrm{KC}$ is an officer of US Stem Cell, Inc. US Stem Cell is a publicly traded company providing physician-based stem cell therapies to human and animal patients as well as a developer of autologous cell therapies.

\section{Ethics Approval and Consent to Participate}

The patient provided written informed consent and agreed to participate in the study.

\section{Consent for Publication}

The patient provided written informed consent and agreed to 
have their data published.

\section{Availability of Data and Materials}

The datasets during and/or analyzed during the current study are available from the corresponding author on reasonable request.

\section{Author Contributions}

$\mathrm{KC}$ and DI designed the protocol. DI was responsible for clinical procedures and follow-up of patient. $\mathrm{KC}$ wrote the manuscript. All authors contributed towards critically revising the paper and agreed to be accountable for all aspects of the work. All authors read and approved the final manuscript.

\section{Abbreviations}

SVF: stromal vascular fraction; ADSCs: adipose-derived stem/ stromal cells; MSC: mesenchymal stem cell; SAE: severe adverse event; AE: adverse event; PRP: platelet-rich plasma

\section{References}

1. Pressure ulcers. Merck Manual Professional Version. http://www.merck.com/mmpe/sec10/ch126/ch126a.html. Accessed June 8, 2018.

2. Rubayi Salah. Etiology and pathology of pressure ulcers. Reconstructive Plastic Surgery of Pressure Ulcers. 2015:5-17.

3. Caplan AI. Mesenchymal stem cells: time to change the name! Stem Cells Transl Med. 2017;6(6):1445-1451.

4. Hematti P, Keating A. Mesenchymal stromal cells in regenerative medicine: A Perspective. In: Hematti P, Keating A, eds. Mesenchymal Stromal Cells. Biology and clinical applications. New York, NY: Humana Press; 2013:3-16.

5. Przybyt E, Harmsen MC. Mesenchymal stem cells: promising for myocardial regeneration? Curr Stem Cell Res Ther. 2013;8(4):270-277.

6. Minteer D, Marra KG, Rubin JP. Adipose-derived mesenchymal stem cells: biology and potential applications. Adv Biochem Eng Biotechnol. 2013;129:59-71.

7. Gimble JM, Katz AJ, Bunnell BA. Adipose-derived stem cells for regenerative medicine. Circ Res. 2007;100(9):1249-1260.

8. Rehman J, Traktuev D, Li J, Merfeld-Clauss S, TemmGrove CJ, Bovenkerk JE, Pell CL, et al. Secretion of angiogenic and antiapoptotic factors by human adipose stromal cells. Circulation. 2004;109(10):1292-1298.

9. Hematti P, Keating A. Mesenchymal stromal cells in regenerative medicine: a perspective. Mesenchymal Stromal Cells. 2012:3-16.

10. Kobolak J, Dinnyes A, Memic A, Khademhosseini A,
Mobasheri A. Mesenchymal stem cells: Identification, phenotypic characterization, biological properties and potential for regenerative medicine through biomaterial micro-engineering of their niche. Methods. 2016;99:6268.

11. Caplan AI, Correa D. The MSC: an injury drugstore. Cell Stem Cell. 2011;9(1):11-15.

12. Traktuev DO, Merfeld-Clauss S, Li J, Kolonin M, Arap W, Pasqualini R, Johnstone BH, et al. A population of multipotent CD34-positive adipose stromal cells share pericyte and mesenchymal surface markers, reside in a periendothelial location, and stabilize endothelial networks. Circ Res. 2008;102(1):77-85.

13. Jang Y, Koh YG, Choi YJ, Kim SH, Yoon DS, Lee M, Lee JW. Characterization of adipose tissue-derived stromal vascular fraction for clinical application to cartilage regeneration. In Vitro Cell Dev Biol Anim. 2015;51(2):142150.

14. Aust L, Devlin B, Foster SJ, Halvorsen YD, Hicok K, du Laney T, Sen A, et al. Yield of human adipose-derived adult stem cells from liposuction aspirates. Cytotherapy. 2004;6(1):7-14.

15. Panfilov IA, de Jong R, Takashima S, Duckers HJ. Clinical study using adipose-derived mesenchymal-like stem cells in acute myocardial infarction and heart failure. Methods Mol Biol. 2013;1036:207-212.

16. Comella K, Parlo M, Daly R, Depasquale V, Edgerton E, Mallory P, Schmidt R, et al. Safety analysis of autologous stem cell therapy in a variety of degenerative diseases and injuries using the stromal vascular fraction. J Clin Med Res. 2017;9(11):935-942.

17. Comella K, Blas JAP, Ichim T, Lopez J, Limon J, Moreno RC. Autologous stromal vascular fraction in the intravenous treatment of end-stage chronic obstructive pulmonary disease: a phase I trial of safety and tolerability. J Clin Med Res. 2017;9(8):701-708.

18. Comella K, Parcero J, Bansal H, Perez J, Lopez J, Agrawal A, Ichim T. Effects of the intramyocardial implantation of stromal vascular fraction in patients with chronic ischemic cardiomyopathy. J Transl Med. 2016;14(1):158.

19. Comella K, Silbert R, Parlo M. Effects of the intradiscal implantation of stromal vascular fraction plus platelet rich plasma in patients with degenerative disc disease. J Transl Med. 2017;15(1):12.

20. Michalek J, Moster R, Lukac L, Proefrock K, Petrasovic M, Rybar J, Capkova M, et al. WITHDRAWN: Autologous adipose tissue-derived stromal vascular fraction cells application in patients with osteoarthritis. Cell Transplant. 2015.

21. Bansal H, Comella K, Leon J, Verma P, Agrawal D, Koka P, Ichim T. Intra-articular injection in the knee of adipose derived stromal cells (stromal vascular fraction) and platelet rich plasma for osteoarthritis. J Transl Med. 2017;15(1):141.

22. Siennicka K, Zolocinska A, Stepien K, Lubina-Dabrowska N, Maciagowska M, Zolocinska E. Adipose-derived cells (stromal vascular fraction) transplanted for orthopedical or neurological purposes: are they safe enough? Stem Cells International. 2016;(2016):1-5. 
23. Comella K, Greenberg S, Ross L. Intra-articular implantation of stromal vascular fraction plus platelet rich plasma in a degenerative meniscal injury. Journal of Medical Cases. 2018;9(7):221-225.

24. Pak J, Lee JH, Lee SH. Regenerative repair of damaged meniscus with autologous adipose tissue-derived stem cells. Biomed Res Int. 2014;2014:436029.

25. Parcero J, Perez J A, Patel A, Ichim T, Gonzalez S, McQuillan S, Comella K. Autologous adipose derived stromal stem cell implantation to resolve critical limb ischemia: case report. Cureus. 2014;6(5):e182.

26. Daumas A, Magalon J, Jouve E, Truillet R, Casanova D, Giraudo L, Veran J, et al. Long-term follow-up after autologous adipose-derived stromal vascular fraction injection into fingers in systemic sclerosis patients. Curr Res Transl Med. 2017;65(1):40-43.

27. Usuelli FG, Grassi M, Maccario C, Vigano M, Lanfranchi L, Alfieri Montrasio U, de Girolamo L. Intratendinous adipose-derived stromal vascular fraction (SVF) injection provides a safe, efficacious treatment for Achilles tendinopathy: results of a randomized controlled clinical trial at a 6-month follow-up. Knee Surg Sports Traumatol Arthrosc. 2018;26(7):2000-2010.

28. Comella K, Bell W. First-in-man intraglandular implantation of stromal vascular fraction and adipose-derived stem cells plus platelet-rich plasma in irradiation-induced gland damage: a case study. Int Med Case Rep J. 2017;10:295-299.

29. Comella K, Parlo M, Daly R, Dominessy K. First-in-man intravenous implantation of stromal vascular fraction in psoriasis: a case study. Int Med Case Rep J. 2018;11:5964.

30. Riordan NH, Ichim TE, Min WP, Wang H, Solano F, Lara F, Alfaro M, et al. Non-expanded adipose stromal vascular fraction cell therapy for multiple sclerosis. J Transl Med. 2009;7:29. 